\title{
MÉMOIRE OUBLIEUSE: POSSÍVEL CONTRIBUIÇÃO “INVOLUNTÁRIA” DE PATRICK MODIANO À NARRATIVA DO PASSADO
}

\author{
Mémoire oublieuse: possible "unintentional" \\ contribution to past story by Patrick Modiano
}

Thiago Tremonte de Lemos*

\begin{abstract}
RESUMO
O presente artigo procura oferecer reflexões a partir da noção de mémoire oublieuse, do escritor francês Patrick Modiano, tomando-a como instrumento possível de métodos historiográficos que tenham como seu principal mote o diálogo interdisciplinar da história com outras áreas do conhecimento, sobretudo no que se refere às potencialidades da memória como fonte para a construção de narrativas do passado.
\end{abstract}

Palavras-chave: mémoire oublieuse; narrativa histórica; mémoire involontaire.

\begin{abstract}
This article aims providing reflections from French writer Patrick Modiano's concept of mémoire oublieuse, taking it as possible instrument of historiographical methods that have the interdisciplinary dialogue of history with other areas of knowledge, especially with respect to the memory potential as source for the construction of past stories its main theme.
\end{abstract}

Keywords: mémoire oublieuse; historical narrative; mémoire involontaire. 


\section{Introdução}

Patrick Modiano não desejou conscientemente - infere-se colaborar de forma concreta para os métodos historiográficos (mesmo aqueles que se apoiam na "memória" como fonte para a pesquisa). Contudo, não são ignoradas contribuições aparentemente involuntárias de outros escritores - como as possibilidades encontradas na noção de mémoire involontaire, da obra de Marcel Proust, por exemplo - como escrutínio metódico para a investigação de narrativas históricas caracterizadas, às vezes, pela ausência de "documentos formais", mas evidenciadas por outras formas humanas de vestígio produzidas e recordadas. A essa afirmação, sabe-se, reabrem-se discussões teóricas em razão de uma "revolução documental" que já fez cair por terra, há muito tempo, certas exclusividades em relação à validade da fonte e, imediatamente, todo e qualquer argumento vindouro é tratado ou como impertinente ou como repetido.

Não obstante, pensa-se que, por mais significativa que tenha sido a incorporação de elementos da literatura - particularmente os de Proust - ou do resultado de outros diálogos interdisciplinares, a escrita da narrativa histórica pode absorver ademais diferentes contribuições de segmentos não científicos. Dessa forma, acredita-se haver na obra de Modiano alguma inspiração para o ofício do historiador.

Por certo, o prestígio de Modiano no meio acadêmico, particularmente no âmbito historiográfico, não alcança ainda o de seu antigo conterrâneo. Não significa, entretanto, ser de todo desconhecido. Basta lembrar que foi laureado com o Prêmio Nobel de Literatura em 2014. Sua influência, contudo, ainda é pouco sentida. Quando o é, destacam-se evidentemente as produções nas áreas de estudos literários. No que se refere à história, desde seu primeiro livro, Modiano ambientou os enredos em cenários historicamente verossímeis e, quiçá, na obra mais "realista" de sua lavra, Dora Bruder (1997), tenha, de fato, executado procedimentos historiográficos na construção de sua narrativa. 
Em 2010, Modiano publicou o romance $O$ horizonte. ${ }^{1}$ Tal obra alcança, possivelmente, o patamar mais alto que o autor pretendera desde 1968, quando apareceu pela primeira vez. Não apenas por construir histórias enredadas pela transição entre a lembrança e o esquecimento, já experimentada por escritos anteriores na confecção das personagens e dos temas, mas por permitir ao leitor - e talvez ao historiador interessado - a percepção de que a construção de uma narrativa não se projeta exclusivamente para o futuro, todavia, mormente para o passado. Este, por sua vez, nunca se dá integralmente: ora é muito vívido, ora completamente apagado. Como o paradoxo não é uniforme (é possível que mesmo a lembrança mais "concreta" seja repleta de "furos"), o passado, ou melhor, a memória do passado também faz esquecer. Sendo assim, a noção que se toma de empréstimo aqui do artigo de Lourdes Carriedo, da Universidad Complutense de Madri, "Écriture, mémoire et structure d'horizon chez Patrick Modiano" (2012), em sua interpretação da obra $O$ horizonte, é a de mémoire oublieuse. Tal conceito (ou método, caso se queira ousar) já se insinuara, ainda em 1978, com Uma rua de $R_{o m a}{ }^{2}$ (pelo qual Modiano recebeu o Prêmio Goncourt e o Prêmio do Romance da Academia Francesa).

O objeto de estudo, no que se refere ao conceito de mémoire oublieuse, não é tão familiar, por isso é necessário deter-se um pouco mais em sua apresentação para que se possa, adequadamente, evocálo pari passu com outras abordagens da memória. Espera-se assim fomentar a reflexão historiográfica acerca das potenciais contribuições da literatura ao tratar dessa noção, as quais são muitas vezes absorvidas e discutidas por diversas áreas do conhecimento, porém, não raro, encontram resistência entre os historiadores. Dessa forma, inicialmente, apoiando-se no artigo supracitado de Carriedo, desenvolver-se-á uma breve descrição do conceito de mémoire oublieuse. Depois, tomar-se-ão também outras obras de Modiano, além de $O$ horizonte, a fim de ilustrar a análise. Em seguida, será discutido, em algumas linhas, o assunto "memória e esquecimento".

1 MODIANO, Patrick. L'Horizon. Paris: Gallimard, 2010.

2 Em francês, o título do livro é Rue des boutiques obscures. MODIANO, Patrick. Uma rua de Roma. Tradução de Herbert Daniel e Cláudio Mesquita. Rio de Janeiro: Rocco, 2014b. 
Por fim, será traçado um paralelo entre os conceitos de mémoire oublieuse e mémoire involontaire na tentativa de inserir o de Modiano, assim como é o de Proust, como uma possibilidade do pensamento historiográfico.

\section{Mémoire oublieuse ${ }^{3}$ na obra de Patrick Modiano}

Uma característica notável no estilo de Modiano é o caráter ambíguo de seus personagens. A dubiedade se estende, consequentemente, ao cenário, ao tempo, ao enredo... Em suas obras, apesar da clareza da escrita, não há certeza jamais sobre os elementos componentes da narrativa. Há, porém, pistas, assim como as têm as personagens (via de regra, há uma investigação em curso). Caso se queira conhecer a história de Dora Bruder (Dora Bruder, 1997), é preciso aceitar resignadamente e, com uma ponta de felicidade, que nem tudo será sabido (trata-se de um tesouro inviolável, escreveu Modiano, ao qual ninguém, nem os nazistas que a eliminaram terão acesso). No caso de Guy Roland, de Uma rua de Roma, personagem e leitor se encontram no mesmo estado de ignorância sobre seu passado. A pesquisa não é apenas de Guy sobre quem ele é, através de suas memórias (que não existem em si, mas são encontradas pela própria personagem, também um detetive), é ainda do leitor.

Neste ponto, faz-se interessante uma observação: o trabalho do historiador é comparado com frequência ao de um detetive, contudo, aceita-se para o segundo um grau de intuição maior do que para o primeiro; do historiador espera-se a comprovação (o que praticamente elimina em sua escrita final alguma tolerância a hipóteses pouco documentadas).

Outro elemento a ser destacado a respeito da escrita de Modiano é certa imagem criada no sentido fotográfico a partir do qual a memória exposta nada mais é do que fragmentos aparentemente

3 Há um livro (e um poema) do escritor franco-uruguaio Jules Supervielle, publicado pela primeira vez em 1949 pela editora Gallimard de Paris, intitulado Oublieuse mémoire. 
desconexos, todavia, ao retomá-los, a mesma memória lhes dá uma dinâmica cinematográfica ${ }^{4}$.

Tomam-se aqui esses dois aspectos mal definidos inicialmente para descrever aquilo que Carriedo entende por mémoire oublieuse. No artigo anteriormente mencionado, Carriedo busca - à luz, sobretudo, do conceito de Michel Collot de "estrutura do horizonte" - refletir sobre a noção de memória e suas expressões na obra de Modiano, particularmente em $O$ horizonte. Segundo a autora, o conceito de Collot considera o horizonte como uma linha que marca os limites da visão e, igualmente, como uma imagem complexa e um aglutinador que reduz e amplia ao mesmo tempo, determina o registro do espaço e do mundo e a constituição das identidades, finalmente, transformando-se em uma estrutura de conhecimento, de pensamento, de imaginação e de expressão ${ }^{5}$. Assim, o horizonte não é apenas fim da visão, mas lugar que marca o que está fora e dentro de seu alcance. A partir dessa primeira definição, pode-se, com a descrição do protagonista de $O$ horizonte feita por Carriedo, encontrar a paradoxal relação que se estabelece entre memória e esquecimento: um sujeito de nome estranho, Bosmans, que busca recompor seu passado juvenil (as pessoas, os lugares, os eventos mais marcantes etc.) como se tentasse formar um quebra-cabeça com peças faltantes.

$\mathrm{O}$ ato de recordar perscruta as coisas, aquilo que se manteve na dupla zona obscura da consciência e do esquecimento, aquilo que permanece desconhecido à visão e à memória, aquilo que se esconde além do esquecimento, além do compreensível, do inteligível, do exprimível. Trata-se dessa 'matéria escura' que todo o

4 CARRIEDO, Lourdes. "Écriture, mémoire et structure d'horizon chez Patrick

Modiano". French Cultural Studies, nov. 2012, p. 342. Disponível em: <http://frc.sagepub.com/content/23/4/341> Acesso em: 7 nov. 2014.

5 Ibidem. 
processo perceptivo e cognitivo implica e do qual a obra O horizonte fala desde o início. ${ }^{6}$

É nesse sentido que Carriedo interpreta, na obra de Modiano, a ação de Bosmans em busca de seu passado opaco como algo a ser descoberto, pois o que se viveu se esconde, é fugaz, todavia, servirá para a compreensão de sua própria vida e dará sentido ao futuro. Desse modo, a noção de memória não convém somente ao resgate do vivido, presta-se a alicerçar um devir igualmente desconhecido.

A mémoire oublieuse, portanto, significa mais do que um exercício investigativo rumo ao passado não integral. É também um esforço para dar sentido à vida através daquilo que foi capturado ou perdido seja pela retina dos olhos ou pela lente da câmara fotográfica, seja pelos sons, odores e sabores. Contudo, ao não ser possível restituí-lo completamente, estabelece-se um limite móvel entre o que é lembrado e esquecido. ${ }^{7}$ Em outras palavras, algo que une e separa ao mesmo tempo. A memória do passado vivido não é exatamente isso? Aproximar e afastar ao mesmo tempo? Ora, se assim for aceita a descrição de Carriedo do conceito de Modiano, esse seria identificável na escrita de outros de seus romances, não apenas em $O$ horizonte. Sabendo-se do encontro entre o ficcional e o histórico em muitos deles, estabelecer-se-ia também uma possibilidade interpretativa da própria história marginalmente narrada pelo escritor $^{8}$, como no caso de Uma rua de Roma.

6 "L'acte de remémoration interroge l'envers des choses, ce qui est resté dans la double zone obscure de la conscience et de l'oubli, ce qui demeure insaisissable au regard et à la mémoire, ce qui se cache au-delà de l'oubli, au-delà du comprehensible, de l'intelligible, de exprimable. Il s'agit... de cette 'matière sombre' que tout processus perceptive et cognitive implique, et dont L'Horizon parle depuis le début' [tradução nossa]. Ibidem, p. 343.

7 Poder-se-ia, talvez, evocar a noção de hímen de Derrida, como sendo o próprio "entre". "Não é nem desejo nem prazer, mas algo intermediário. Nem futuro nem presente, mas o intermediário. É o hímen que deseja sonhos de perfuração, de romper em um ato de violência que é (ao mesmo tempo ou em algum ponto intermediário) amor e assassinato. Se um deles chegasse a acontecer, não haveria hímen (...). É como uma operação que tanto semeia a confusão entre opostos como também se coloca entre os opostos 'a uma só vez"' (DERRIDA, J. Dissemination. Tradução de B. Johnson. Chicago: Chicago University Press, 1981, pp. 212-223 apud BHABHA, Homi K. O local da cultura. Tradução de Myriam Ávila, Eliana Lourenço de Lima Reis e Gláucia Renate Gonçalves. Belo Horizonte: Ed. UFMG, 1998, p. 182).

8 Com exceção, em parte, de Dora Bruder. 
Antes, porém, é preciso detalhar a noção de que as imagens evocadas pela memória, em Modiano, aparecem também como fotografias. Recorre-se, destarte, às reflexões de Annelies Schulte Nordholt, da Universiteit Leiden, no artigo "Photographie et image en prose dans Dora Bruder de Patrick Modiano" (2011). Desde o início do livro Dora Bruder, a (re)construção dos cenários feita por Modiano - que atua, particularmente nessa obra, como um investigador da história real da adolescente Dora Bruder - é quase a de um curador ao buscar conferir ordem à exposição de algum acervo ou a de um arquivista diante de documentos fotográficos. Para tanto, se dispõe a descrever minuciosamente o que vê em suas "fotos".

Segundo Nordholt, ao apresentar a imagem do bairro onde Dora Bruder passou sua infância, por exemplo, no início do livro, Modiano o faz através da rememoração fotográfica, ainda que as imagens não sejam reproduzidas, mas apenas mencionadas ${ }^{9}$. Concomitantemente à discussão sobre a memória como fotografia, trata-se do conceito de "pós-memória". Isso significa que a investigação de Modiano não se faz somente na recuperação de documentos oficiais ou a partir de entrevistas ou encontros com personagens que eventualmente pudessem ter ou não alguma pista sobre a história de Dora Bruder. Tampouco com as imagens (fotográficas) dos espaços possíveis frequentados por Dora, a qual também os conheceu. Sua narrativa precisou, ainda, apoiar-se na memória de outrem, tanto na do próprio pai do autor como na de Dora, uma vez que Modiano, em pessoa, não vivenciou qualquer acontecimento antes de 1945, ano de seu nascimento. Dessa forma:

Sua memória é uma 'pós-memória', segundo o termo de Marianne Hirsch: uma memória por procuração, tomada de empréstimo por relatos, da vida dos outros, vivida de outra maneira, de um outro tempo (...). Dora Bruder -

9 NORDHOLT, Annelies Schulte. Photographie et image en prose dans Dora Bruder de Patrick Modiano. Neophilologus, v. 96, n. 4, p. 526. Disponível em: <http://link.springer.com/article/10.1007\%2Fs11061-011-9288-7> Acesso em: 9 fev. 2015. 
seu sobrenome Bruder significa irmão em alemão - é em certo sentido irmã de Modiano. ${ }^{10}$

Seguindo o argumento de Nordholt, no que se refere agora à maneira como Modiano lidou com as fotografias encontradas em sua pesquisa sobre Dora Bruder "real", há de se levar em consideração a noção de Roland Barthes acerca da fotografia: a imagem como índice (seja ela real ou fictícia ${ }^{11}$ ), como prova tangível do que foi, também sugere que o que foi não é mais, que desapareceu. Nesse sentido e convenientemente, aproxima-se a dubiedade própria do estilo de Modiano: "a fotografia está entre a vida e a morte". ${ }^{12}$ Ou seja, os eventos do passado são evocados, mas não revelados na câmara escura (assim como se as fotografias estivessem apenas em filme).

Eurídice Figueiredo, da Universidade Federal Fluminense, em estudo comparado de Uma rua de Roma, de Modiano, e Austerlitz (2001), de W. G. Sebald, discute a noção de "pós-memória" nas duas obras. De acordo com Figueiredo, a "pós-memória" é aquela de eventos vivenciados por outros intimamente ligados aos escritores. Sendo, portanto, uma homenagem. Do mesmo modo que Carriedo, ao descrever rapidamente o enredo do livro e, particularmente o protagonista (nesta obra, também o narrador), Figueiredo encontra a

10 'Sa mémoire est une 'postmémoire', selon le terme de Marianne Hirsch: une mémoire par procuration, empruntée aux récits, à la vie des autres, vécue de manière différée, retardée (...). Dora Bruder - comme son nom de Bruder, significant 'frère' en allemand, l'indique, aux yeux de certains - est dans un certain sens une soeur de Modiano" [tradução nossa]. Ibidem, p. 529.

11 Nesse caso, entende-se que a posição de Barthes pode ser ampliada exatamente nos encontros diversos entre a história e a imaginação ocorrida nas narrativas romanceadas. "Outro dia, reli o romance de Thomas Mann A Montanha Mágica. Esse livro traz à cena uma doença que conheci bem, a tuberculose; pela leitura, eu tinha reunidos, em minha consciência, três momentos dessa doença: o momento da anedota, que se passa antes de 1914, o momento de minha própria doença, por volta de 1942, e o momento atual em que esse mal, vencido pela quimioterapia, não tem mais o mesmo rosto de outrora. Ora, a tuberculose que eu vivi é, com mínimas diferenças, a tuberculose dA Montanha Mágica: os dois momentos se confundiam, igualmente afastados de meu próprio presente. Percebi com estupefação (só as evidências podem estupefazer) que meu próprio corpo era histórico". BARTHES, Roland. Aula: aula inaugural da cadeira de semiologia literária do Colégio da França, pronunciada em 7 de janeiro de 1977. Tradução de Leyla Perrone-Moisés. São Paulo: Cultrix, 2007, pp. 43-44. p. 533 .

12 "la photographie est entre la vie et la mort" [tradução nossa]. NORDHOLT. Op. cit., 
ideia de montar um quebra-cabeça sem ter todas as peças: "porque ao juntar os elementos desse puzzle nem todas as peças são encontradas e montadas". ${ }^{13}$ Outro elemento de aproximação na reflexão das duas pesquisadoras é a compreensão do caráter "arquivista" dos personagens de Modiano. Não basta encontrar as memórias. É preciso ordená-las. Para Carriedo, "metódico, de espírito arquivista, esse personagem, de estranho nome Bosmans, anota em uma caderneta de moleskine preto as imagens incompletas, as sequências suspensas, os traços de certas experiências e impressões que sobreviveram a destruição do tempo". ${ }^{14}$ Para Figueiredo, por sua vez, a noção "arquivística" do protagonista de Uma rua de Roma vai além: algo que pode ser mais do que compreendido, ser reinterpretado.

Guy (...) tem a seu dispor os arquivos do antigo escritório (...), catálogos telefônicos e anuários de todos os tipos dos últimos cinquenta anos, que lhe são de extrema utilidade em sua investigação (...). Jacques Derrida assinala a importância de reelaborar hoje o conceito de arquivo (...), aponta para lógica do arquivo, que estoca várias camadas a serem escavadas pelo arqueólogo (o escritor) em busca de restos ou rastros do passado. Como se trata de uma história rasurada, a recuperação do passado pela escrita (literária ou mesmo historiográfica) vai juntar e rearrumar os dados do passado. Pode-se conceber esta sobreimpressão de elementos como um palimpsesto a ser decifrado, a ser recomposto e ressignificado. ${ }^{15}$

13 FIGUEIREDO, Eurídice. A pós-memória em Patrick Modiano e W. G. Sebald. Alea: Estudos Neolatinos, v. 15, n. 1, Rio de Janeiro, jan-jun. 2013, p. 3. Disponível em: <http://dx.doi.org/10.1590/s1517-106X2013000100009> Acesso em: 28 abr. 2015.

14 "Méthodique, à l'esprit archiviste, ce personage, au nom étrange de Bosmans, note sur un carnet de moleskine noire les images incompletes, les sequences en suspens, les traces de certaines experiences ou impressions qui ont survecú à la destruction du temps" [tradução nossa]. CARRIEDO. Op. cit., p. 342.

15 FIGUEIREDO. Op. cit., pp. 3-4. 
Aqui a extensão do argumento à historiografia é conveniente. A memória incompleta "por natureza" preenche as lacunas com os documentos arquivados, levando o investigador não apenas à compreensão do passado, mas ressignificando-o. Além de ressignificação, como paradoxo. Ricoeur, ao tratar da "memória do esquecimento", a partir de Santo Agostinho, afirma que o esquecimento é, ao mesmo tempo, paradoxo e enigma. Tanto no que se refere à impossibilidade de falar sobre um esquecimento absoluto (pois se se deslembra, sabe-se que há algo esquecido) quanto a um impedimento para resgatar o tempo passado em sua manifestação fenomênica original. Finalmente, pode-se citar Ricoeur, ao se aproximar da "memória" proustiana e perceber que esta também carrega a dubiedade necessária da lembrança e do esquecimento.

Quanto ao par evocação/recordação, a reflexividade está em seu auge no esforço de recordação; ela é enfatizada pelo sentimento de penosidade ligada ao esforço; a evocação simples pode, nesse aspecto, ser considerada como neutra ou não marcada, na medida em que se diz que a lembrança sobrevém como presença do ausente; pode-se dizer que ela é marcada negativamente nos casos de evocação espontânea, involuntária, bem conhecida dos leitores da Busca (...) proustiana. ${ }^{16}$

\section{Memória e esquecimento}

A retomada do passado é ambígua. Não se consegue plenamente rememorar tudo que é vivido, ainda que esquecê-lo por inteiro seja possível. Entretanto, não saber (ou ainda "esquecer") não é necessariamente uma categoria total de ausência. Ainda que assim

16 RICOEUR, Paul. A memória, a história, o esquecimento. Tradução de Alain François et al. Campinas, SP: Editora da Unicamp, 2007, p. 55. 
fosse, o fato de nada existir poderia denunciar claramente que já não o é, pois algo aconteceu. ${ }^{17}$

Segundo Paolo Rossi, existem duas tradições filosóficas que, de alguma forma, permanecem no pensamento contemporâneo concernentes à memória (/lembrança) e ao (olvido/) esquecimento: a primeira entende o esquecimento como algo que corresponde à perda de fragmentos - temporária ou permanente - de experiências, sensações, imagens, ideias etc. antes presentes na consciência individual e coletiva. Esta noção "... foi construída e foi ficando mais complexa a partir de contribuições que provinham (e provêm) da psicologia, psicanálise, psicopatologia, neurofisiologia, antropologia, sociologia e narrativa...". Já a segunda concebe o esquecimento como a perda da totalidade da experiência e da história humanas e “... não tem interesse algum nas contribuições que provêm dos campos específicos da cultura (Freud, Proust ou Edelmann)". ${ }^{18}$ Filia-se aqui, evidentemente, à primeira tradição, uma vez que não se admite a totalidade da perda, tampouco da reconstrução plena do acontecido. $\mathrm{O}$ que de certo modo leva a uma percepção da memória não apenas ligada ao passado "... mas também com a identidade e, assim (indiretamente), com a própria persistência no futuro". ${ }^{19}$

Ainda conforme pensou Rossi - tomando a afirmação de David Lowenthal como ponto de partida -, a história é mais e menos que o passado $^{20}$ :

17 Ilustra-se esta ideia com um elementar exemplo da colonização da América: em algumas ilhas do Caribe, antes habitadas por civilizações que hoje desapareceram por completo, não há a negação de sua existência. Não há necessidade, muitas vezes, de encontrar seus rastros. A própria ausência deles é a prova contundente do crime que foi a colonização e da existência das mesmas civilizações. Édouard Glissant, por sua vez, entende que tal ausência pode ser concebida como um "rastro/resíduo inconsciente". "Geralmente, no Caribe, o problema não se apresenta, porque os ameríndios foram todos exterminados, com exceção de um reduzido número que se encontra em uma reserva da ilha de São Domingos. O remanescente atávico do Caribe passa por uma espécie de rastro/resíduo inconsciente". GLISSANT, Édouard. Introdução a uma poética da diversidade. Tradução de Enilce do Carmo Albegaria Rocha. Juiz de Fora, MG: Editora UFJF, 2005 , p. 73.

18 ROSSI, Paolo. O passado, a memória, o esquecimento: seis ensaios da história das ideias. Tradução de Nilson Moulin. São Paulo: Editora UNESP, 2010, pp.18-19.

19 Ibidem, p. 24.

20 LOWENTHAL, David. "Imaged Pasts: Reconstructing History". In: BIANCHI, M. L. (org.). Storia delle Idee: Problemi e Prospettive. Roma: Edizioni dell'Ateneo, 1989, pp. 134-155 apud ROSSI. Op. cit. 2010, p. 28. 
... é certamente possível, deste ponto de vista, contrapor a história, que é interpretação e distanciamento crítico do passado, à memória, que implica sempre uma participação emotiva em relação a ele, que é sempre vaga, fragmentária, incompleta, sempre tendenciosa em alguma medida... A história e a memória coletiva podem ser pensadas como as duas pontas de uma antinomia: em que os avanços da historiografia fazem continuamente retroceder o passado imaginário que foi construído pela memória coletiva. ${ }^{21}$

Finalmente, para Rossi, "O entrelaçamento de memóriaesquecimento é muito profundo. Mesmo quando se teorizam rupturas totais e irreparáveis e transformações radicais". ${ }^{22}$ Implicando não apenas o resgate ou o apagamento do passado em si, mas suas potenciais projeções de futuro, como forma de lembrar/esquecer para superá-lo.

A memória, de natureza dúbia, é também esquecimento. Além do mais, ela sempre é criativa. Nada do que é lembrado é de outra forma senão de certa maneira. O debate acerca do tema não é novo. Há, contudo, reflexões das quais o assunto aqui proposto parece se aproximar mais intimamente. É o caso dos ensaios de Jeanne Marie Gagnebin, reunidos no livro Lembrar escrever esquecer (2009), especialmente, "O que significa elaborar o passado?". O modo como expõe o debate contemporâneo sobre a memória já é uma boa síntese das relações estabelecidas, sobretudo, entre o conhecimento e a memória.

Na história, na educação, na filosofia, na psicologia o cuidado com a memória fez dela não só um objeto de estudo, mas também uma tarefa ética: nosso dever consistiria em preservar a memória, em salvar o 
desaparecido, o passado, em resgatar, como se diz, tradições, vidas, falas e imagens. ${ }^{23}$

Se se trata de um dever ético, como lidar com aquilo perdido, já desaparecido? O esquecimento, mais do que a memória, não é voluntário (pelo menos, não na maior parte das vezes). A construção do passado, ao lidar objetivamente com suas lacunas, permite uma relação menos mistificadora da memória. Aliás, a memória pela memória poderia produzir uma espécie um tanto saturada e esvaziada do sentido pedagógico e de outras potencialidades na lembrança do passado. $\mathrm{O}$ esquecimento ou, ainda, aquilo que não pode ser alcançado também teria valor para o historiador interessado, tanto por indicar que a ausência não é necessariamente casual como para investigar possibilidades de destruição da própria memória: "devemos lembrar o passado, sim; mas não lembrar por lembrar, numa espécie de culto ao passado". ${ }^{24}$

As reflexões de Gagnebin (referentes à obra de Walter Benjamin sobre Proust e Kafka) serão retomadas posteriormente. Entretanto, destaca-se aqui uma preciosa passagem do ensaio "Verdade e memória do passado", acerca da sexta tese de Benjamin sobre o conceito de história. ${ }^{25}$ Segundo a interpretação de Gagnebin, Benjamin recusaria à história a condição ideal de ciência. Tal posição estaria sustentada por princípios políticos, éticos e epistemológicos. ${ }^{26}$ Interessam particularmente as razões epistemológicas (ainda que a autora afirme que são inseparáveis das demais). Primeiramente porque a impossibilidade de recuperar a história em sua integralidade não inviabiliza a narrativa da história, pois esta sempre se faz de algum modo. Esse modo é uma articulação ${ }^{27}$ e não uma descrição.

23 GAGNEBIN, Jeanne Marie. Lembrar escrever esquecer. São Paulo: Editora 34, 2009 , p. 97.

24 Ibidem, p. 103.

25 "Articular historicamente o passado não significa conhecê-lo 'como de fato foi'. Significa apropriar-se de uma reminiscência, tal como ela relampeja no momento de um perigo" BENJAMIN, Walter. Magia e técnica, arte e política: ensaios sobre literatura e história da cultura. Tradução de Sérgio Paulo Rouanet. São Paulo: Brasiliense, 1994 (Obras Escolhidas v. 1), p. 224.

26 GAGNEBIN. Op. cit. 2009, p. 40.

27 "É o caso de se perguntar se a suspeita não é inteiramente forjada a partir de um modelo linguístico inapropriado ao discurso histórico, o qual seria mais bem entendido a partir de 
Com alguma liberdade, portanto, relacionam-se a essa opinião dois trechos de outras teses sobre o conceito de história de Benjamin. Da segunda, há algo possivelmente já intuído neste artigo. O passado, por não ser completo, apresenta-se através de vestígios, rastros, ou melhor, como índice. Para Benjamin, citando a referida passagem um pouco modificada, "o passado traz consigo um índice misterioso (...). Não existem, nas vozes que escutamos, ecos de vozes que emudeceram? (...) Se assim é, existe um encontro secreto, marcado entre as gerações precedentes e a nossa". ${ }^{28}$

A noção de que o trabalho "científico" do historiador não se apoia no paradigma (galileano) de ciência e possui outro estatuto é reforçada por Carlo Ginzburg em seu ensaio "Sinais: raízes de um paradigma indiciário". Uma vez que o conhecimento do historiador não pode ser ontológica e epistemologicamente construído em termos universais, o saber da história se faz na decifração dos indícios legados pelo passado. "Se a realidade é opaca, existem zonas privilegiadas - sinais, indícios - que permitem decifrá-la". ${ }^{29}$ Ginzburg ainda pergunta se mesmo assim o conhecimento amparado em tal paradigma indiciário correria o risco de não ser considerado rigoroso. Para o autor:

A orientação quantitativa e antiantropocêntrica das ciências da natureza a partir de Galileu colocou as ciências humanas num desagradável dilema: ou assumir um estatuto científico frágil para chegar a resultados relevantes, ou assumir um estatuto científico forte para chegar a resultados de pouca relevância. Só a linguística conseguiu, no decorrer deste século, subtrair-se a esse

modelos alternativos para os quais o referente, qualquer que seja ele, constitui uma dimensão irredutível de um discurso dirigido por alguém a alguém sobre alguma coisa. Faltaria dar conta da especificidade da referencialidade em regime historiográfico. Minha tese é que ela não pode ser discernida unicamente no plano do funcionamento das figuras que o discurso histórico assume, mas deve transitar pela prova documental, pela explicação causal/final e pela composição literária. Tal arcabouço tríplice continua a ser o segredo do conhecimento histórico". RICOEUR. Op. cit., p. 263. 28 BENJAMIN. Op. cit. 1994, p .223.

29 GINZBURG, Carlo. Mitos, emblemas, sinais: morfologia e história. Tradução de Federico Carotti. São Paulo: Companhia das Letras, 1989, p. 177. 
dilema, por isso pondo-se como modelo, mais ou menos atingido, também para as outras disciplinas. ${ }^{30}$

Na quinta tese sobre o conceito de história de Benjamin, a ideia de que a imagem do passado é fugaz, capturada apenas de relance, como um clarão (ou uma fotografia), permite entender que, do mesmo modo que a lembrança se torna um exercício imprescindível (ético) para o historiador, lidar com aquilo que não será de forma alguma capturado também é. Não conhecer tudo ou aquilo que não está capturado pela imagem não é sempre algo tão lamentável. Se se deve lembrar para não esquecer o horror do extermínio de judeus durante a Segunda Guerra Mundial, igualmente, é vedado ao carrasco conhecer tudo de sua vítima. Assim como escreveu Modiano sobre Dora Bruder - objeto do escritor. Em sua pesquisa de oito anos sobre a história de Dora, há dois períodos - que antecedem a apreensão da jovem e, posteriormente, a de seu pai, seu envio para o leste europeu, em 18 de setembro de 1942, e, consequentemente, seu assassinato no campo de extermínio de Auschwitz - sobre os quais Modiano nada descobriu. No entanto, nesse caso, a ausência de informações - ou da memória - é, para o escritor, positiva.

Nunca irei saber como ela passava os dias, qual era seu esconderijo, a quem via durante os meses de inverno de sua primeira fuga, e durante as semanas da primavera, quando novamente fugiu. Aí está o seu segredo. Um simples mas precioso segredo que os algozes, os decretos, as autoridades ditas da Ocupação, a prisão, os quartéis, os campos, a História, o tempo - tudo aquilo 
que nos empresta e nos destrói - nunca mais lhe poderão roubar. $^{31}$

Se o passado fugidio escorre por entre os dedos das mãos e não se pode agarrá-lo por inteiro, aquilo que se perde para o esquecimento nem sempre prejudica o entendimento do passado. Por vezes, a sensação da ausência, o sentimento de que falta algo é mais forte do que a tímida presença de um dado concreto. Cabe aqui, por conseguinte, outra breve consideração feita por Paul Ricoeur sobre o "esquecimento". Deixando de lado as significativas reflexões desenvolvidas acerca dos aspectos científicos neurais, bem como a rica discussão filosófica da obra de Henri Bergson, Matéria e memória ${ }^{32}$ toma-se um pequeno mas inspirador trecho da terceira parte (exatamente sobre o "esquecimento") da "Nota de orientação". No que se refere à ambiguidade encontrada entre memória e esquecimento e também em algum nível de positividade, ainda que como dúvida do último, Ricoeur lança mão da fábula de Jorge Luis Borges "Funes el memorioso" (1942), sobre o homem que nada esquecia. ${ }^{33}$ Supondo haver alguma medida adequada para o uso da memória humana, "o esquecimento não seria, portanto, sob todos os aspectos, o inimigo da memória, e a memória deveria negociar com o esquecimento para achar, às cegas, a medida exata de seu equilíbrio com ele?". ${ }^{34}$ Ora, até mesmo do ponto de vista hermenêutico, há a necessidade de se evitar a totalidade da memória como última representação da condição histórica. Aliás, encontra-se em outra obra de Bergson, A evolução criadora, a ideia que mais se aproxima dessa positividade, ainda que relativa, acerca do esquecimento. Ao tratar do que é exterior e interior do objeto à percepção, como estado da consciência, o autor assim escreve:

31 MODIANO, Patrick. Dora Bruder. Tradução de Maria Cavalcanti Ribas Vieira. Rio de Janeiro: Rocco, 2014a, p. 137.

32 BERGSON, Henri. Matière et mémoire. Paris: Quadrige: PUF, 1939, 2012.

33 Segundo Paolo Rossi, "Uma patologia da lembrança [grifos do autor], uma monstruosidade 'por execesso', não é apenas invenção do gênio literário de Borges. Ele apresentou seu relato como 'uma longa metáfora da insônia', mas com frequência a realidade supera até a fantasia dos escritores mais fantasiosos". ROSSI, Op. cit. 2010, p. 40.

34 RICOEUR. Op. cit., p 424. 
Um ser que não fosse dotado de memória ou de previsão nunca proferiria nesse caso as palavras 'vazio' ou 'nada'; exprimiria simplesmente aquilo que é e aquilo que ele percebe. Ora, aquilo que é e aquilo que se percebe é sempre a presença disto ou daquilo, nunca a ausência seja do que for. Só existe ausência para um ser capaz de recordar e esperar. Recordava um objeto e esperava talvez voltar a encontrá-lo: encontra outro diferente e exprime a decepção da sua expectativa, nascida da recordação [grifos do autor]. ${ }^{35}$

\section{Memórias: Hugo, Proust e Modiano}

O olfato, esse misterioso auxiliar da memória, acabava de fazer reviver-lhe no íntimo um mundo inteiro. Victor Hugo

As reminiscências provocadas pelos odores são, na busca do passado, as mais singelas. Em Proust, a memória do olfato ganha importância. No entanto, não era de todo desconhecida na literatura francesa. Nas páginas finais d'Os miseráveis, Hugo faz referência a ela. $\mathrm{O}$ caso que narra, todavia, não é propriamente feliz ${ }^{36}$, ainda que a

35 BERGSON, Henri. A evolução criadora. Tradução de Adolfo Casais Monteiro. São Paulo: Ed. Unesp, 2010, p. 307.

36 Em relação a esse aspecto, Gagnebin é categórica ao tratar da perspectiva de que, na obra de Proust, a mémoire involontaire não manifestaria apenas sensações felizes e, portanto, não se deveria interpretar Em busca do tempo perdido como uma procura dos encontros felizes entre as sensações e o passado. Aliás, ao comparar trechos de outros livros de Proust com a da "madeleine" de Em busca..., Gagnebin se reporta a uma passagem de No caminho de Swann (a visita da mãe do narrador ao seu quarto à noite e a insinuação de um amor incestuoso por parte da criança) e demonstra que, mesmo no primeiro dos livros - o da infância propriamente dita -, encontram-se também, na mémoire involontaire, lembranças amargas do passado infantil: "ao redor do núcleo central que descreve a experiência propriamente dita, temos uma introdução muito maior sobre a miséria da memória voluntária, do esforço consciente de lembrar o passado (em oposição à felicidade da memória involuntária que o episódio da 'madeleine' ilustra), assim como alguns 
lembrança do "cheiro do tabaco" se ofereça como uma pista desejada pela personagem Marius Pontmercy. Não cabe aqui recontar o ocorrido, mas quem se lembra das últimas páginas do romance sabe o que esse momento significou antecedendo o desfecho da trama. Também em outras circunstâncias do livro, Hugo se remete à memória - seja a sua própria ou a das personagens - e, igualmente, ao esquecimento (seu ou de suas personagens). Como exercício para reconstruir a cidade de Paris ou a história da França ou a sua própria, sente-se a vontade do escritor de deixar mais do que uma obra-prima da literatura, um ponto de vista sobre a história francesa do século XIX.

O contexto do enredo se desenvolve nas três primeiras décadas dos oitocentos, mas Hugo escreveu boa parte do livro no início da década de 1860 . De uma forma ou de outra, não há como abandonar uma história apenas à imaginação; tampouco aos fatos comprovadamente documentados. Misturam-se lembranças, desejos, sonhos, invenções, eventos etc. Enfim, mesmo a memória mais vívida, ainda assim é memória e, se involuntariamente surge, no cheiro do tabaco ou do chá da tia-avó, sensações distintas àquelas premeditadas diante de um acontecimento transformam a própria percepção da realidade. Foi assim com a personagem de Hugo e com as personagens de Proust e Modiano.

Le Goff recorda convenientemente a obra de Bergson, Matéria e memória, percebendo a expansão das reflexões acerca da memória no âmbito da literatura e do conhecimento humano.

(...) central a noção de 'imagem', na encruzilhada da memória e da percepção. No termo de uma longa análise das deficiências da memória (amnésia da linguagem ou afasia) descobre, sob uma memória superficial, anônima, assimilável ao hábito, uma memória profunda, pessoal,

desenvolvimentos, também muito maiores, a respeito da morte do passado para nós". GAGNEBIN. Op. cit., 2009, p. 149. 
'pura', que não é analisável em termos de 'coisas', mas de 'progresso'. 37

Dessa forma - e por uma delimitação do escopo restringem-se aqui os estudos sobre a memória e as diversas áreas de conhecimento que se debruçam sobre o objeto. É evidente que o presente trabalho não lida com outra forma da memória que não esteja no nível concebido como "memória social" (individual ou coletiva) ou, ainda mais precisamente, aquilo que Le Goff percebeu como uma nova memória romanesca que "restabelece a cadeia "mito-históriaromance", ${ }^{38}$ como a obra Em busca do tempo perdido. Também é explícito - contudo convém reforçar - que esta reflexão não busca encontrar as causas biológicas de qualquer modalidade da memória ${ }^{39}$, mas como esta, em uma dimensão da narrativa - ora real, ora ficcional -, pode servir ao trabalho historiográfico.

Walter Benjamin conhecia bem os escritos de Proust e valorizou sua mémoire involontaire para além dos limites do romance. Obviamente, não poderia saber nada acerca da noção de memória utilizada por Modiano em suas obras, mormente o que se salientou aqui sobre a ideia de esquecimento. Contudo, também era admirador e estudioso de Kafka. Nesse ponto, pode-se, inicialmente, sugerir um primeiro encontro entre as duas "memórias", ainda que a segunda se faça demonstrar através da produção de outro escritor. Com isso, não há a pretensão de afirmar que Modiano é continuador de Kafka ou mesmo asseverar prematuramente a influência kafkiana nos trabalhos de Modiano, mas uma vez que Benjamin foi comentador tanto de Kafka quanto de Proust, julga-se adequada, nesse particular, a aproximação mencionada.

Quanto ao que escreveu sobre e influenciado por Proust, há em seu ensaio "A imagem de Proust", de 1929, sobre o conceito de

37 LE GOFF, Jacques. História e memória. Tradução de Bernardo Leitão [et al]. Campinas, SP: Editora da Unicamp, 2003, p. 465

38 Ibidem.

39 "O discurso sobre a memória é muito antigo. Nenhum indivíduo poderia memorizar todos os títulos que, desde a Antiguidade até hoje, fazem referência à memória. Mas é importante sublinhar que esse tema não se identifica e não se esgota nem com o tema das artes da memória nem com os problemas das neurociências". ROSSI, Op. cit. 2010, p. 23. 
mémoire involontaire, uma célebre passagem mais do que pertinente. Benjamin entende que a ferramenta encontrada para reviver o passado em Em busca do tempo perdido - a mémoire involontaire - serve como condensador do tempo em um aspecto interno (a reminiscência) e outro externo (o envelhecimento). Tal condensação não produz nada mais senão um rejuvenescimento do passado. Ou seja, a partir da manifestação de uma lembrança promovida pela mémoire involontaire, a sensação - ou melhor, a percepção - se faz como algo conhecido e ao mesmo tempo novo. "É a obra da mémoire involontaire, da força rejuvenescedora capaz de enfrentar $\mathrm{o}$ implacável envelhecimento". ${ }^{40}$

Proust já percebera isso desde o primeiro livro de Em busca do tempo perdido: No caminho de Swann (Benjamin, em Infância em Berlim por volta de $1900,{ }^{41}$ parece seguir alguns procedimentos de Proust). A abordagem do tema no último livro, Tempo redescoberto, como solução para reencontrar o tempo perdido, para além de toda a criatividade literária, se dá pelo recurso à imaginação e o escritor, em sua vocação inata para o romance, o faz em razão de seus enredos e, também, a fim de se encontrar com as próprias experiências vividas. Por um lado, há a necessidade de localizar as provas, os fatos, os dados esclarecedores do passado; por outro, a necessidade de senti-lo. E como não é possível fazê-lo em seu grau mais elevado quando efetivamente se experimenta a realidade, o fato, o evento, o acontecimento etc., ele se torna mais "forte" quando lembrado sem intenção. ${ }^{42}$ A empresa de Proust, portanto, não é somente uma boa fórmula para o escritor encontrar uma apropriada fonte de inspiração

40 BENJAMIN. Op. cit. 1994, p. 45

41 BENJAMIN, Walter. Rua de mão única. Tradução de Rubens Rodrigues Torres Filho e José Carlos Martins Barbosa. São Paulo: Brasiliense, 2012 (Obras Escolhidas v. 2).

42 "Como teria qualquer valor a literatura descritiva, se a realidade se oculta sob pequenas coisas que enumera (a grandeza no ruído distante de um aeroplano, na linha do campanário de Saint-Hilaire, o passado de uma madeleine etc.) e por si mesmas nada significam, se não souber desentranhar o que encerram? Pouco a pouco conservada pela memória, é a cadeia de todas as impressões inexatas, onde nada resta do que realmente sentimos, que constitui para nós nosso pensamento, nossa vida, a realidade, e é essa falsidade reproduzida pela arte dita 'vivida', simples como a vida, sem beleza, duplo emprego do que veem nossos olhos e verifica nossa inteligência, tão fastidioso e vão que indagamos onde encontra quem a cultiva a flama alegre e motora capaz de animá-lo, de fazê-lo prosseguir na tarefa". PROUST, Marcel. O tempo redescoberto. Tradução de Lúcia Miguel Pereira. São Paulo: Globo, 2004 (Em busca do tempo perdido, v. 7), pp.171-172. 
para seus romances (também para isso, óbvio); serve de exemplo àqueles que pretendem conhecer e se aproximar sensivelmente dos eventos experimentados, tantos seus como de outros.

De modo similar, nesse aspecto, pode-se entender que Modiano, especialmente em Dora Bruder, recorre a lembranças surgidas não por vontade. Contudo, não seria o caso de pensar a mémoire oublieuse mais nítida em $O$ horizonte, mas um esboço e um encontro possível entre as duas "memórias". Há aqui duas situações: primeiramente, durante sua investigação sobre a história real de Dora Bruder, encontra momentos de contato com sua própria lembrança. Não do que vivenciou, pois Dora fora assassinada antes de o escritor nascer, mas das histórias rememoradas por seu pai ${ }^{43}$, as quais o afetaram de tal modo que sua projeção ao período de ocupação da França pelas tropas alemãs é forte (não neste necessariamente, mas em outros romances) a ponto de ser capaz de descrever o sombrio ambiente com grande imaginação. Em segundo lugar, por encontrar, ao longo de sua pesquisa, informações que o remeteram a outras lembranças, como no caso da descoberta de que Dora, apesar de (e talvez exatamente por) ser judia, foi internada em um colégio pensionato católico para meninas, na Rue de Picpus em Paris. A rua era conhecida na cidade por reunir um bom número desse tipo de instituição. Quando Modiano encontrou tal informação, outra recordação involuntariamente se apresentou ao seu pensamento: o bairro do Petit-Picpus d'Os miseráveis de Victor Hugo.

Para ser desenvolvido o presente argumento, é preciso um pouco de paciência. Começa-se por Hugo. Em 1848, a obra foi deixada de lado pelo autor; em 1851, Hugo abandonou Paris e a França por razões políticas e se exilou até 1870. Somente em 1861, retomou o romance. Sendo assim, ao descrever a cidade, o fez com o concurso de sua memória, nem sempre certeira. No caso que se verifica aqui, trata-se de uma importante passagem do segundo tomo

43 "Talvez eu desejasse que ela e meu pai se tivessem conhecido nesse inverno de 1942. Por mais diferentes que fossem um e outro, ambos tinham sido reprovados naquele inverno. Meu pai não se recenseou em outubro de 1940 e, como Dora Bruder, não usava o número do 'processo judeu'. Assim, não possuía existência legal nenhuma, e tinha cortado todas as amarras com um mundo onde era preciso que cada um tivesse um trabalho, uma família, uma nacionalidade, uma data de nascimento, um domicílio. De agora em diante, ele estava fora. Um pouco como Dora, depois da fuga”. MODIANO. Op. cit. 2014a, p. 59). 
da obra, Cosette, do quinto ("Caça tenebrosa, matilha silenciosa") e do sexto ("Petit-Picpus") livros. O herói, Jean Valjean, acompanhado da órfã Cosette, tenta escapar da perseguição promovida pelo inspetor Javert. Em determinado momento, Valjean e Cosette entram em um obscuro bairro da cidade de Paris, o Petit-Picpus. Lá conseguem invadir um convento - o das bernardas beneditinas da Adoração Perpétua, também pensionato, localizado na Rue de Picpus, $n^{\circ} 62$-, escondendo-se da polícia.

Como mencionado, Hugo retomou a obra após uma década sem contato com Paris. Particularmente nessa cena (ambientada no início da década de 1820), podem ser identificadas duas características que se apresentam em Modiano e que o remetem também à mémoire involontaire de Proust. A primeira é a imaginação de Hugo, pois este inventa uma geografia de Paris. O bairro do PetitPicpus não existe. Também não existia até 1848 e nem passou a existir com as profundas reformas urbanísticas sofridas pela cidade a partir da segunda metade do século XIX, exatamente no momento em que Hugo se encontrava no exílio. A segunda tem a ver com Modiano ao se lembrar da obra de Hugo no momento em que descobria o lugar onde se achava Dora Bruder, pouco tempo antes de ser capturada e enviada para o campo de Drancy e, posteriormente, a Auschwitz.

Notam-se diferentes formas aqui de se conectar com a memória. Pode-se afirmar, ainda, que o esquecimento, nesse sentido, permite algum grau de preservação das coisas como eram ou ainda como deveriam ser. A obra Os miseráveis é conhecida mesmo por quem jamais leu uma única linha do livro, entretanto, quantos foram aqueles que perceberam uma conexão entre a história de uma adolescente judia, a shoah, Jean Valjean, Cosette e Javert? Ah, e o pai de Modiano também. Enfim, apenas para reforçar a mistura que se deu entre memória e esquecimento, história e romance: o bairro do Petit-Picpus não existe; a Rue de Picpus existe; Valjean, Cosette e Javert são personagens fictícios; Dora Bruder e o pai de Modiano são (ou eram) reais. Tal entendimento pode ser ilustrado com algumas longas passagens d'Os miseráveis e de Dora Bruder. Incluir-se-á, igualmente, um trecho de $O$ caminho de Guermantes, para se reestabelecer a conexão entre Proust e Modiano.

De Hugo: 
Faz muitos anos que o autor (...) está ausente de Paris. Depois de sua saída, Paris se transformou. Levantou-se uma nova cidade que, de algum modo, lhe é completamente desconhecida. Não é necessário dizer que ele gosta de Paris; Paris é a cidade natal de sua alma. Por uma série de demolições e reconstruções, a Paris de sua juventude, aquela Paris que ele guarda religiosamente na memória, é a esta hora uma Paris antiga. Permitam-lhe, portanto, falar de Paris como ele a conheceu. É bem possível que o autor conduza os leitores a alguns lugares dizendo: - Em tal rua há uma casa assim -, e já não exista nem a casa nem a rua. Se quiserem dar-se a esse trabalho, poderão verificar. Quanto ao autor, ele ignora a nova Paris, e escreve com a antiga Paris diante dos olhos, em uma ilusão que lhe é muito cara (...). Para ele, é um consolo pensar que ainda resta alguma coisa do que conheceu quando estava em seu país natal e que nem tudo mudou. Enquanto vivemos na nossa terra, parecenos que aquelas ruas nos são indiferentes, que aquelas janelas, telhados e portas nada significam, que aquelas paredes são completamente estranhas, que aquelas árvores nasceram ontem, que aquelas casas, onde nunca entramos, são inúteis, que as ruas por onde andamos não passam de simples pedras. Mais tarde, quando estamos longe, é que percebemos como nos são queridas aquelas ruas, como nos fazem falta aqueles telhados, aquelas janelas e portas, como nos são indispensáveis aquelas paredes, como gostamos daquelas árvores, como aquelas casas, onde nunca entramos, faziam parte da nossa vida, e que deixamos entranhas, sangue e coração nas pedras daquelas ruas. Todos esses lugares, que não vemos mais, que talvez nunca mais tornaremos a ver, e cuja imagem guardamos em nossa mente, tomam um encanto nostálgico, voltam com a melancolia e uma aparição, tornam-nos visível a terra santa e são, podemos dizer, a própria alma da França; então, gostamos de relembrá-las tais como as conhecemos, do mesmo modo, obstinadamente, sem querer mudar coisa alguma, porque a imagem da pátria é como o retrato de uma mãe (...). 
Seja-nos, portanto, permitido falar do passado no presente. $^{44}$

\section{De Proust:}

Entre a cor cinzenta e suave de uma campina matinal e o gosto de uma xícara de chocolate, inseria eu toda a originalidade da vida física, intelectual e moral que levara cerca de um ano antes a Doncières, e que, brasonada com a forma oblonga de uma colina calva sempre presente ainda quando invisível - formava em mim uma sucessão de prazeres inteiramente diversos de quaisquer outros, indizíveis para os amigos, no sentido que as impressões ricamente entretecidas umas nas outras que os orquestravam muito mais os caracterizavam para mim, e sem que eu soubesse, do que os fatos que eu poderia contar. Desse ponto de vista, o mundo novo em que o nevoeiro daquela manhã me havia mergulhado era um mundo já meu conhecido (o que só lhe dava mais verdade), e esquecido desde algum tempo (o que lhe devolvia todo o seu frescor). E eu pude contemplar alguns dos quadros de bruma que minha memória havia adquirido, notadamente vários 'Manhã em Doncières', ou no primeiro dia no quartel, ou de outra vez, num castelo próximo, a que Saint-Loup me levara a passar vinte e quatro horas; da janela cujas cortinas eu havia soerguido pela madrugada, antes de tornar a deitar-me, no primeiro, um cavaleiro, no segundo (na estreita linde de um pântano e de um bosque de que todo o resto se achava mergulhado na suavidade uniforme e líquida da bruma), um cocheiro a lustrar uma correia, me haviam aparecido como essas vagas personagens, mal distinguidas pela

44 HUGO, Victor. Os miseráveis. v. 1 e 2. Tradução de Frederico Ozanam Pesooa de Barros. São Paulo: Cosac Naify, 2012, pp. 633-634. De algum modo parecido, Proust projeta sua Combray, sua Balbec e, por que não, sua Paris (ainda que vivesse nela durante a escrita de Em busca do tempo perdido). É importante lembrar que, pouco antes de sua morte, Proust se isolou em sua residência a fim de dedicar-se exclusivamente à obra, tendo pouco contato com o mundo exterior. 
vista obrigada a adaptar-se ao vago misterioso das penumbras, que emergem de um afresco apagado. ${ }^{45}$

\section{E de Modiano:}

Em 9 de maio de 1940, Dora Bruder, com 14 anos, foi internada num estabelecimento religioso, obra do Sagrado Coração de Maria, dirigido pelas irmãs das Escolas Cristãs da Misericórdia, nos números 60 e 62 da rua de Picpus (...). Escrevo estas páginas em novembro de 1996 (...) no meio da agitação, custo a acreditar que estou na mesma cidade de Dora Bruder e seus pais, e também a do meu pai quando ele tinha 20 anos a menos do que eu. Tenho a impressão de que estou inteiramente só, ao fazer este paralelo entre a Paris daquele tempo e a de hoje, única pessoa a lembrar-se de todos esses detalhes. Por instantes, o elo se enfraquece e parece que vai romper, em algumas noites, a cidade de ontem parece em reflexos fortuitos, atrás da de hoje (...). Reli os volumes quinto e sexto de Os miseráveis (...), em geral, experimenta-se uma sensação de vertigem, como se Cosette e Jean Valjean, para escapar de Javert e dos policiais, caíssem no vazio: até então eles cruzavam as ruas de uma Paris real, e, de repente, são lançados em um bairro de uma Paris imaginária, que Victor Hugo chama de Petit Picpus. Esta sensação de estranheza é a mesma que sentimos quando caminhamos, distraídos, por um bairro desconhecido. Quando despertamos, percebemos aos poucos que as ruas desse bairro estão como que superpostas às que nos são familiares durante o dia (...). Como muitos outros antes de mim, acredito pessoalmente nas coincidências, e, às vezes, no dom de vidência dos escritores - a palavra 'dom' não é o termo exato, já que sugere uma espécie de superioridade. Não, isso faz parte da profissão: os esforços de imaginação, necessários nessa profissão, a necessidade de fixar o espírito em

45 PROUST, Marcel. O caminho de Guermantes. Tradução de Mario Quintana. São Paulo: Globo, 2007 (Em busca do tempo perdido, v. 3), pp. 378-379. 
pontos, detalhes - de maneira até obsessiva - para não perder o fio da meada, deixando-se ir de forma aleatória - toda essa tensão, essa ginástica cerebral, pode certamente provocar, a longo prazo, breves intuições 'relativas a acontecimentos passados ou futuros', como está escrito no dicionário Larousse, no tópico 'Vidência'. 46

É bem verdade, entretanto, a falibilidade científica do conhecimento do passado aqui proposto. Não é disso que se trata. $\mathrm{O}$ importante é perceber o resultado que o movimento engendrado pela mémoire involontaire tem na narrativa do passado e no modo como leitor e autor chegam até ele. Ao se recordar de todas as experiências vividas - das mais singelas da infância às mais tórridas de sua juventude -, Proust não tomou de imediato a dimensão de sua novidade na relação entre memória e história. Somente quando, também involuntariamente, nota sua vocação e sua obrigação ética como escritor, sua ideia de recuperar o passado se torna nítida. ${ }^{47}$

Em relação aos comentários de Benjamin sobre a obra de Franz Kafka, restringir-se-ão àqueles sobre $O$ processo, uma vez que entende-se ter, a partir da interpretação de Willy Haas, um lugar especial para a noção de "esquecimento": "o objeto deste processo, o verdadeiro herói desse livro inacreditável, é o esquecimento (...), cujo principal atributo é o de esquecer-se a si mesmo (...). O esquecimento é o receptáculo a partir do qual emergem à luz do dia os contornos do inesgotável mundo intermediário, nas narrativas de Kafka”. ${ }^{48}$ Sendo assim, da trama que se desenvolve no livro de Kafka acerca do julgamento de Joseph K., Benjamin sugere que há - apesar da angustiante ignorância - alguma possibilidade de redenção no esquecimento, como escreveu Gagnebin. 
Se o esquecimento é, portanto, a culpa essencial em Kafka, uma culpa que só pode ser expiada sem ser conhecida, estes vestígios do esquecido, como Odradek ou o Corcundinha da 'Infância Berlinense' indicam, paradoxalmente, o caminho de uma esperança possível mesmo se ela não existir para nós (...), mesmo se nem o estudo, nem a oração, nem a escrita conseguem alcançála. ${ }^{49}$

Aqui já se faz sentir uma possível aproximação com a ideia de mémoire oublieuse proposta por Carriedo na obra de Modiano. Se em Kafka, o esquecimento já apresentara uma dupla carga moral culpa e esperança -, ele é tomado mais livremente por Modiano. Tal qual o paradoxo kafkiano, as personagens, os cenários, os contextos e os enredos de Modiano trazem, na íntima relação entre memória e esquecimento, as duas possibilidades, sendo que ambas são imiscíveis, todavia capazes de coabitar o mesmo espaço. Além disso, a memória para Modiano não se faz apenas com as experiências dos eventos por si, mas de outrem. A reconstrução do passado, voluntária ou involuntária (mais involuntária, afirma-se), é uma mistura de presenças e ausências rememoradas, não apenas por aqueles que estiveram ali. Aliás, a noção de presente também se altera, uma vez que o contato que se tem com as informações do passado - seja pela memória esquecida, seja pelo acesso a algum vestígio documental ou rastro material - cria, no presente, uma inédita representação desse mesmo passado, indicando novas sensações e entendimentos, acarretando, consequentemente, uma nova história. A memória e o esquecimento, duas faces da mesma moeda, servem então como um critério; em outras palavras, não é possível lançar mão de um sem o outro. Nenhum tem em si uma positividade ou negatividade - o que facilmente poderia ser pensado em relação aos dois - ao operarem concomitantemente, ao se aproximarem ao mesmo tempo em que se afastam, o escritor e também o historiador podem perceber de forma transitória, mas ainda destacada, os limites entre o fato e a ausência,

49 GAGNEBIN, Jeanne Marie. História e narração em Walter Benjamin. São Paulo: Perspectiva, 1999, pp. 68-69. 
entre o "real" e o "fictício", entre o vivido e a possibilidade não realizada da experiência, enfim, entre o que é lembrado e o que é olvidado.

Retomando as interpretações de Figueiredo, entende-se que Modiano e Proust estariam próximos. Para a autora, na obra Uma rua de Roma, ao trabalhar com a noção de "pós-memória" na busca de Guy Roland (protagonista do romance) por seu passado e, consequentemente, por sua identidade, Modiano não valoriza a "memória voluntária", mas, sim, a mémoire involontaire.

\begin{abstract}
À semelhança de Proust, que no último volume da Recherche tem uma sequência de experiências sensoriais que o levam a rememorar acontecimentos antigos, o personagem-narrador de Modiano, ao sair do prédio, sente um segundo estalo, diante da luminosidade produzida por um globo que espalhava uma luz branca, um pouco excessiva (...). O processo de recuperação (parcial) da memória se dá através de elementos sensoriais. ${ }^{50}$
\end{abstract}

Seria no mínimo pretensioso acreditar que as aproximações apresentadas são inquestionáveis. Sabe-se, sobretudo, do imprescindível reexame das hipóteses e dos argumentos construídos. Entretanto, como exercício de reflexão sobre as possíveis contribuições da "memória" de Modiano para a narrativa histórica, pensa-se como avanço. Não porque se alcançou o fim premeditado (isso não era nítido no início das elucubrações), porém, ao se sugerir a experiência de outras fontes da memória - não exclusivamente aquelas já territorializadas pelo fazer historiográfico - como factíveis ao trabalho do historiador, revelam-se novos horizontes $\mathrm{e}$ perspectivas, tanto no que se refere à delimitação das zonas do que é ou não ficção, quanto na impossibilidade humana de realizar qualquer distinção plena entre o acontecimento e a imaginação que o narrou (ou recordou). "A escrita da história partilha dessa forma das

50 FIGUEIREDO. Op. cit., p. 6 
aventuras da composição em imagens da lembrança sob a égide da função ostensiva da imaginação". 51

Também seria exagero pensar em algum instrumento conceitual definido. Contudo, em certas análises, falta o termo adequado - ainda que temporário - para especificar a lacuna entre eventos que não foram integralmente rememorados. Para as testemunhas da história, esse termo sempre foi - e com correção - a apresentação de documentos comprobatórios. $\mathrm{O}$ mesmo não se faz com aqueles que tiveram a oportunidade de ouvi-las. Quanto aos confidentes que receberam o segredo do passado, espera-se deles exatamente isso: que nada contem. Ora, se a mémoire involontaire tem mais força que a recordação voluntária, pois escapa da própria vontade consciente, a mémoire oublieuse se transforma em limite entre o recordável e o esquecível, não como barreira, mas como articulador que une e separa ao mesmo tempo. O historiador talvez devesse perceber isso: o esquecimento não é sempre a negação da memória; é a única possibilidade de se notar que aí havia alguma coisa... agora, esquecida.

RECEBIDO EM: 23/03/2016 APROVADO EM: 05/11/2016 